\title{
УХУДШЕНИЕ ДЕМОГРАФИЧЕСКОЙ СИТУАЦИИ В РОССИЙСКОЙ ФЕДЕРАЦИИ В СОВРЕМЕННЫХ УСЛОВИЯХ
}

\author{
(c) 2021 Бабич Светлана Гаврииловна \\ кандидат экономических наук, доцент, доцент кафедры статистики \\ Российский экономический университет имени Г. В.Плеханова, Россия, Москва \\ E-mail:Babich.SG@rea.ru
}

В статье представлены результаты изучения динамики численности населения, числа родившихся и умерших в Российской Федерации и федеральных округах страны в условиях вспышки коронавирусной инфекции COVID-19. Выявлены основные факторы, оказывающие влияние на демографическую ситуацию в стране. Произведена группировка субъектов РФ по величине коэффициента естественного прироста населения; выделены регионы страны со сложной демографической ситуацией, а также регионы с благоприятной демографической ситуацией.

Ключевые слова: население, рождаемость, смертность, естественный прирост, коэффициент естественного прироста, динамика

Экономическое и социальное развитие отдельного субъекта Российской Федерации и страны в целом зависит от множества как внешних, так и внутренних факторов. Основными внешними факторами, по нашему мнению, являются объем иностранных инвестиций в российскую экономику, величина внешнего долга РФ, объем внешней торговли с различными государствами, позиционирование России в мировом сообществе. Внутренние факторы, такие как, численность населения, в том числе занятых в экономике; Валовой внутренний (региональный) продукт; объем основных фондов; объем инвестиций в основной капитал; уровень инфляции; объем затрат на технологические инновации; объем инновационных товаров, работ, услуг и т.д. оказывают существенное влияние на сложившуюся социально-экономическую ситуацию в нашей стране. Из важнейших внутренних факторов особое место занимает не только абсолютная величина численности населения, но демографическая ситуация в целом, под которой обычно понимают демографическую обстановку, состояние демографических процессов в стране или отдельном регионе $[4$, с. 41$]$.

В соответствии с Указом Президента РФ от 09.10.2007 № 1351 «Демографическая политика Российской Федерации направлена на увеличение продолжительности жизни населения, сокращение уровня смертности, рост рождаемости, регулирование внутренней и внешней миграции, сохранение и укрепление здоровья населения, и улучшение на этой основе демогра- фической ситуации в стране» [1].

Вспышка новой коронавирусной инфекции COVID-19 в мире не обошла стороной и нашу страну, в результате чего осложнилась демографическая ситуация. В Российской Федерации в 2020 г. численность населения сократилась на 577575 чел. (на 0,39\%) и на 1 января 2021 г. по данным Федеральной службы государственной статистики (Росстата) составила 146171015 чел. Необходимо отметить, что только в двух федеральных округах страны - Южном и СевероКавказском - наблюдается рост численности населения на $0,10 \%$ и $0,37 \%$ соответственно. Наиболее существенное уменьшение жителей в абсолютном выражении отмечается в Центральном федеральном округе - на 577575 человек, а в относительном выражении - в Приволжском федеральном округе (на 0,74\%) (табл. 1).

Несмотря на ежегодное увеличение численности населения страны 2010-2018 гг., в 2019 число жителей РФ снизилось на $0,07 \%$.

Из 82 субъектов РФ, по которым проводилось исследование, только в 14 регионах страны в течение 2020 г. число жителей возросло: Московская обл., Калининградская обл., Ленинградская обл., Республика Адыгея, Краснодарский край, г. Севастополь, Республика Дагестан, Республика Ингушетия, Кабардино-Балкарская Республика, Чеченская Республика, Тюменская обл., Республика Алтай, Республика Тыва, Республика Саха (Якутия)., в остальных регионах нашей страны в 2020 г. отмечается сокращение численности населения (табл. 2). 
Таблица 1. Динамика численности населения в федеральных округах РФ

\begin{tabular}{|l|c|c|c|c|}
\hline \multirow{2}{*}{\multicolumn{1}{c|}{ Федеральный округ }} & \multicolumn{2}{|c|}{ Численность населения } & \multicolumn{2}{c|}{ Изменение численности населения, } \\
\cline { 2 - 5 } & на начало года, тыс. чел. & 2021 г. & тыс. чел. & тыс. чел. \\
\hline Центральный & 2020 г. & 39250960 & -182596 & $-0,46$ \\
\hline Северо-Западный & 13981992 & 13941959 & -40033 & $-0,29$ \\
\hline Южный & 16466084 & 16482488 & 16404 & 0,10 \\
\hline Северо-Кавказский & 9930933 & 9967301 & 36368 & 0,37 \\
\hline Приволжский & 29287683 & 29070827 & -216856 & $-0,74$ \\
\hline Уральский & 12360752 & 12329500 & -31252 & $-0,25$ \\
\hline Сибирский & 17118387 & 17003927 & -114460 & $-0,67$ \\
\hline Дальневосточный & 8169203 & 8124053 & -45150 & $-0,55$ \\
\hline
\end{tabular}

Источник: рассчитано и составлено по данным Росстата [10]

Таблица 2. Число субъектов Российской Федерации по динамике численности населения в 2020 г.

\begin{tabular}{|l|c|c|c|}
\hline \multirow{2}{*}{ Федеральный округ } & \multirow{2}{*}{ Число субъектов - всего } & в том числе по изменению численности населения \\
\cline { 2 - 4 } & 18 & увеличение & уменьшение \\
\hline Центральный & 10 & 1 & 8 \\
\hline Северо-Западный & 8 & 2 & 5 \\
\hline Южный & 7 & 4 & 14 \\
\hline Северо-Кавказский & 14 & - & 3 \\
\hline Приволжский & 4 & 1 & 10 \\
\hline Уральский & 10 & 2 & 8 \\
\hline Сибирский & 11 & 1 & 3 \\
\hline Дальневосточный & 11 & 3 \\
\hline
\end{tabular}

Источник: рассчитано и составлено по данным Росстата [10]

Снижение численности населения в конкретном регионе может происходить вследствие естественного и (или) миграционного движения населения. Поскольку в 2020 г. естественная убыль населения (абсолютная величина разности между числами родившихся и умерших) составила по данным Росстата 688,7 тыс. чел., то анализируя динамику численности населения в субъектах РФ более целесообразно, по нашему мнению, подробно рассмотреть показатели естественного движения населения.

В нашей стране в течение 2020 г. несмотря на принимаемые Правительством Российской Федерации меры по улучшению демографической ситуации, число родившихся уменьшилось на 3,3\% по сравнению с 2019 г. Их всех федеральных округов только в Северо-Кавказском федеральном округе наблюдается рост числа родившихся на $2,4 \%$. А наиболее значительное уменьшение числа родившихся в относительном выражении произошло в Северо-Западном и Сибирском федеральных округах - на 5,0\% и $4,6 \%$ соответственно. В условиях ухудшения эпидемиологической обстановки в стране на фоне сокращения рождаемости существенно увеличилось число умерших (на 18,0\%). В наибольшей степени рост числа умерших наблюдается в Северо-Кавказском и Приволжском федеральных округах - на $22,4 \%$ и $21,1 \%$ соответственно (табл. 3).

Как отмечают эксперты, снижение рождаемости - это комплексная проблема, которая затрагивает все сферы жизнедеятельности человека. Существуют факторы, способные косвенно или напрямую повлиять на динамику рождаемости. К таким факторам можно отнести доход населения, здоровье, количество регистрируемых браков, современные представления о семье [2, с. 102].

K факторам, обуславливающих снижение числа родившихся в стране, можно отнести также, по нашему мнению, сокращение чис- 
Таблица 3. Динамика числа родившихся и умерших в федеральных округах Российской Федерации

\begin{tabular}{|c|c|c|c|c|c|c|}
\hline \multirow{2}{*}{ Федеральный округ } & \multicolumn{2}{|c|}{$\begin{array}{c}\text { Число родившихся, } \\
\text { человек }\end{array}$} & \multirow{2}{*}{$\begin{array}{c}\text { Темп } \\
\text { прироста,\% }\end{array}$} & \multicolumn{2}{|c|}{$\begin{array}{c}\text { Число умерших, } \\
\text { человек }\end{array}$} & \multirow{2}{*}{$\begin{array}{c}\text { Темп } \\
\text { прироста,\% }\end{array}$} \\
\hline & 2019 г. & 2020 г. & & 2019 г. & 2020 г. & \\
\hline Центральный & 369324 & 354092 & $-4,1$ & 497901 & 590455 & 18,6 \\
\hline Северо-Западный & 133996 & 127327 & $-5,0$ & 173412 & 202022 & 16,5 \\
\hline Южный & 161564 & 156577 & $-3,1$ & 210842 & 243668 & 15,6 \\
\hline Северо-Кавказский & 133293 & 136446 & 2,4 & 72431 & 88627 & 22,4 \\
\hline Приволжский & 281470 & 270041 & $-4,1$ & 379872 & 459950 & 21,1 \\
\hline Уральский & 135480 & 131122 & $-3,2$ & 144688 & 171335 & 18,4 \\
\hline Сибирский & 178345 & 170145 & $-4,6$ & 221529 & 256396 & 15,7 \\
\hline Дальневосточный & 91045 & 90000 & $-1,1$ & 100002 & 112026 & 12,0 \\
\hline
\end{tabular}

Источник: рассчитано и составлено по данным Росстата [10]

ленности женщин в репродуктивном возрасте, продолжающуюся урбанизацию населения, сокращение реальных денежных доходов населения; рост уровня безработицы.

По мнению исследователей Института демографических исследований ФНИСЦ РАН, в России снижению смертности населения препятствует процесс постарения населения, а также нисходящая структурная демографическая волна, ведущая к сокращению доли молодого населения и росту доли населения пенсионного возраста; постоянное относительное снижение уровня жизни населения; инертность изменения вредных привычек, таких как курение и злоупотребление алкоголем; плохая экология в целом ряде крупных промышленных городов и мегаполисов страны; кардинально не улучшающееся плохое качество питания и алкоголя; и т.п. [3, с.182-183].

В стране в 2020 г. во всех федеральных округах страны, кроме Северо-Кавказского федерального округа, число умерших граждан значительно превышает число родившихся, что означает естественную убыль населения. Применение абсолютных показателей демографической статистики не в полной мере отражает сложившуюся ситуацию, в связи с чем целесообразно, по нашему мнению, произвести анализ относительных показателей, характеризующих число родившихся, умерших и величину естественного прироста в регионе в течение календарного года в расчете на 1000 человек населения. В России общий коэффициент рождаемости населения, показывающий число родившихся в течение календарного года в расчете на 1000 человек населения, в 2020 г. составил 9,8 (для сравнения в 2019 г. аналогичный показатель составлял 10,1$)$, а общий коэффициент смертности, т.е. число умерших в течение календарного года в расчете на 1000 человек населения, возрос с 12,3 в 2019 г. до 14,5 в 2020 г.

Коэффициент естественного прироста населения, показывающий величину естественного прироста населения в расчете на 1000 человек населения, в 2020 г. по данным Росстата составил $-4,7$ (для сравнения в 2019 г. был равен -2,2), отрицательное значение которого свидетельствует об естественной убыли населения. В 2019 г. и 2020 г. только в Северо-Кавказском федеральном округе наблюдался естественный прирост населения, т.е. сохраняется превышение числа родившихся над числом умерших в расчете на 1000 человек населения на 6,2 чел. и 4,8 чел. соответственно В других федеральных округах страны значение данного коэффициента различается. Например, в 2020 г. в Центральном федеральном округе в расчете на 1000 человек населения естественная убыль населения составляла 6,0 человек, а в Дальневосточном федеральном округе - 2,7 человек (рис. 1).

В 2020 г. по данным Росстата в 71 регионе (из 82 субъектов) наблюдается естественная убыль населения. Наиболее значительная проблемы в демографической сфере сохраняются в Тульской области, в которой естественная убыль населения в расчете на 1000 человек населения составила 11,3 чел., Псковской (10,9 чел.), Владимирской (10,7 чел.), Тамбовской (10,4 чел.) и Тверской (10,4 чел.) областях. В 2020 г. высокий естественный прирост населения в расчете на 1000 жителей традиционно сохраняется в Чеченской Республике (14,0 чел.), Республике Ингушетия (12,9 чел.), Республике Дагестан (8,7 чел.) и Республике Тыва (10,8 чел.) (табл. 4).

Как видно из табл. 4, во всех регионах Центрального, Северо-Западного, Южного и При- 


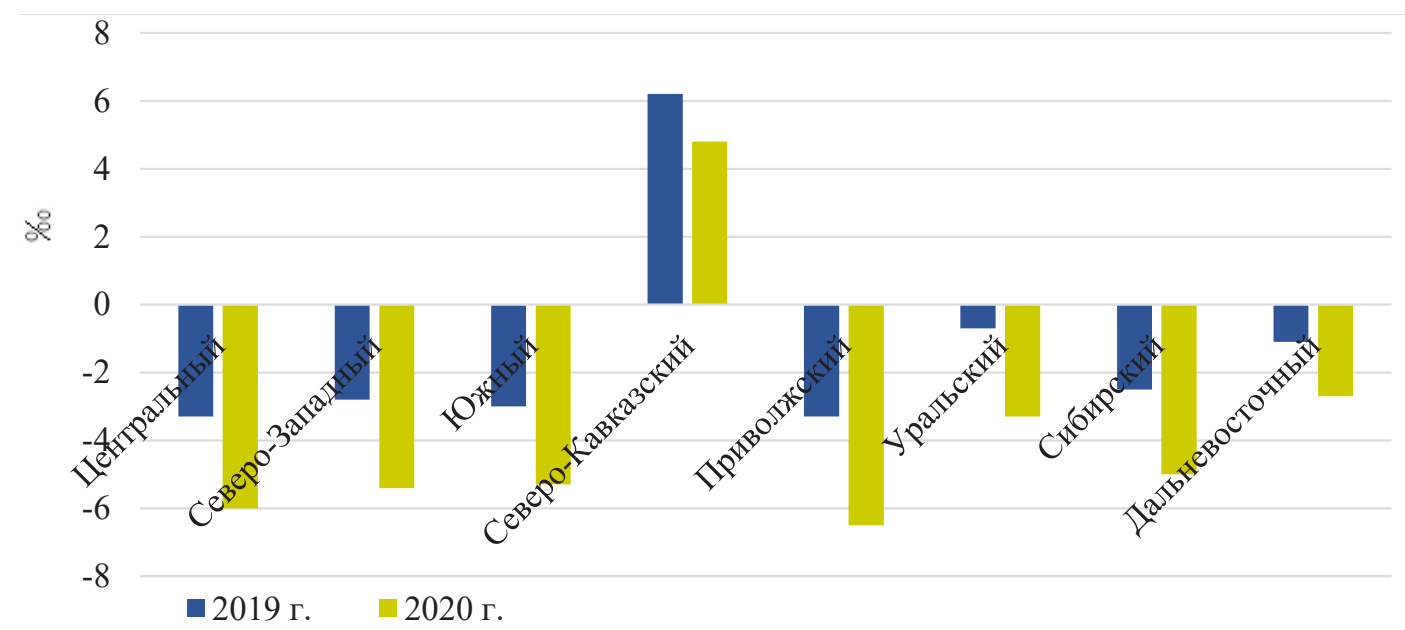

Рисунок 1. Динамика коэффициента естественного прироста населения в федеральных округах РФ, промилле

Таблиц̧а 4. Группировка субъектов РФ по величине коэффициента естественного прироста населения в 2020 г.

\begin{tabular}{|c|c|c|}
\hline $\begin{array}{l}\text { Коэффициент } \\
\text { естественного } \\
\text { прироста } \\
\text { населения }\end{array}$ & Федеральный округ & Субъекты РФ \\
\hline \multirow{2}{*}{ более -10,0 } & Центральный & $\begin{array}{l}\text { Владимирская обл., Орловская обл., Тамбовская обл., Тверская обл., } \\
\text { Тульская обл. }\end{array}$ \\
\hline & Северо-Западный & Псковская обл. \\
\hline \multirow{4}{*}{ от - 10,0 до -8,0 } & Центральный & $\begin{array}{l}\text { Брянская обл., Воронежская обл., Ивановская обл., Калужская обл., } \\
\text { Курская обл., Липецкая обл., Рязанская обл., Смоленская обл., Ярос- } \\
\text { лавская обл. }\end{array}$ \\
\hline & Северо-Западный & Респ. Карелия, Новгородская обл. \\
\hline & Приволжский & $\begin{array}{l}\text { Респ. Мордовия, Кировская обл., Нижегородская обл., Пензенская } \\
\text { обл., Саратовская обл., Ульяновская обл. }\end{array}$ \\
\hline & Уральский & Курганская обл. \\
\hline \multirow{7}{*}{ от $-8,0$ до $-6,0$} & Центральный & Белгородская обл., Костромская обл. \\
\hline & Северо-Западный & Архангельская обл., Вологодская обл., Ленинградская обл. \\
\hline & Южный & Респ. Крым, Волгоградская обл., Ростовская обл. \\
\hline & Приволжский & Чувашская Респ., Оренбургская обл., Самарская обл. \\
\hline & Уральский & Челябинская обл. \\
\hline & Сибирский & Алтайский кр., Кемеровская обл., Омская обл. \\
\hline & Дальневосточный & Амурская обл. \\
\hline \multirow{7}{*}{ от $-6,0$ до $-4,0$} & Центральный & Московская обл. \\
\hline & Северо-Западный & Респ. Коми, Мурманская обл. \\
\hline & Южный & г. Севастополь \\
\hline & Приволжский & Респ. Башкортостан, Респ. Марий Эл, Удмуртская Респ., Пермский кр. \\
\hline & Уральский & Свердловская обл. \\
\hline & Сибирский & Новосибирская обл., Томская обл. \\
\hline & Дальневосточный & Приморский кр., Хабаровский кр., Еврейская ав. обл. \\
\hline
\end{tabular}


Продолжение Таблицы 4

\begin{tabular}{|c|c|c|}
\hline \multirow{6}{*}{ от $-4,0$ до $-2,0$} & Северо-Западный & Калининградская обл., г. Санкт-Петербург \\
\hline & Южный & Респ. Адыгея, Краснодарский кр., Астраханская обл. \\
\hline & Северо-Кавказский & Ставропольский кр. \\
\hline & Приволжский & Респ. Татарстан \\
\hline & Сибирский & Респ. Хакасия, Красноярский кр., Иркутская обл \\
\hline & Дальневосточный & Камчатский кр., Магаданская обл., Сахалинская обл. \\
\hline \multirow{4}{*}{ от $-2,0$ до 0,0} & Центральный & г. Москва \\
\hline & Южный & Респ. Калмыкия \\
\hline & Северо-Кавказский & Респ. Северная Осетия - Алания \\
\hline & Дальневосточный & Забайкальский кр., \\
\hline \multirow{2}{*}{ от 0,0 до 2,0 } & Северо-Кавказский & Карачаево-Черкесская Респ. \\
\hline & Дальневосточный & Респ. Бурятия, Чукотский авт. окр. \\
\hline \multirow{3}{*}{ от 2,0 до 4,0} & Северо-Кавказский & Кабардино-Балкарская Респ. \\
\hline & Уральский & Тюменская обл. \\
\hline & Сибирский & Респ. Алтай \\
\hline от 4,0 до 6,0 & Дальневосточный & Респ. Саха (Якутия) \\
\hline от 6,0 до 8,0 & - & - \\
\hline \multirow{2}{*}{ более 8,0} & Северо-Кавказский & Респ. Дагестан, Респ. Ингушетия, Чеченская Респ. \\
\hline & Сибирский & Респ. Тыва \\
\hline
\end{tabular}

Источник: составлено по данным Росстата [10]

волжского федеральных округах в 2020 г. отмечается естественная убыль населения. О негативной тенденции свидетельствует не только сокращение числа субъектов Российской Федерации, в которых наблюдается естественный прирост населения, с 14 регионов 2019 г. до 11 регионов в 2020 г., но и значения показателей естественного прироста населения: если в 2019 г. в 14 регионах страны естественная убыль населения в расчете на 1000 человек составляла 6,0 чел. и более, то в 2020 г. количество таких регионов возросло до 40 (табл. 5).

По мнению экспертов Института демографических исследований ФНИСЦ РАН, пандемия коронавируса COVID-19 является новым дополнительным фактором, препятствующим успешному демографическому развитию России. Во-первых, помимо прямых людских потерь, растет уровень смертности от косвенных последствий коронавируса; во-вторых, частично отложены рождения детей в отдельных стратах населения; в-третьих, снизился приток переселенцев и трудовых мигрантов в РФ [3, с. 183].

Сокращение рождаемости означает снижение численности рабочей силы, что приводит в итоге к увеличению демографической нагрузки на трудоспособное население. В то же время, уменьшение численности активной трудоспособной части населения приведет к невозможности не только количественного, но и качественного воспроизводства высоко квалифицированных профессиональных кадров. [4, с. 141].

Как отмечается в Указе Президента РФ «О национальных целях и стратегических задачах развития Российской Федерации на период до 2024 года» в стране необходимо обеспечить увеличение суммарного коэффициента рождаемости до 1,7 и снижение показателей смертности населения трудоспособного возраста (до 350 случаев на 100 тыс. населения) [5]. В 2019 г. суммарный коэффициент рождаемости в стране составил по данным Росстата 1,5.

Для достижения поставленной цели по улучшению демографической ситуации в стране необходимо по мнению экспертов, мобилизовать все возможные резервы увеличения рождаемости (сокращение числа абортов, снижение возраста первых рождений, увеличение числа двух-трехдетных семей, повышение доли юридически оформленных браков за счет сокращения так называемых гражданских и пр.) [6, с. 64].

Улучшить ситуацию в демографической сфере могут меры, предпринимаемые Правитель- 
Таблица 5. Распределение субъектов РФ по значению коэффициента естественного прироста населения

\begin{tabular}{|c|c|c|c|c|c|c|c|c|c|c|c|}
\hline \multirow[b]{2}{*}{ Федеральный округ } & \multicolumn{11}{|c|}{$\begin{array}{c}\text { Число субъектов РФ по значению коэффициента } \\
\text { естественного прироста населения }\end{array}$} \\
\hline & 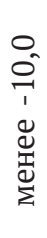 & $\begin{array}{l}0 \\
0 \\
\infty \\
1 \\
0 \\
0 \\
0 \\
0 \\
0 \\
1 \\
1 \\
0\end{array}$ & $\begin{array}{l}0 \\
0 \\
1 \\
0 \\
0 \\
0 \\
\infty \\
1 \\
5 \\
0\end{array}$ & $\begin{array}{l}0 \\
0 \\
f \\
1 \\
0 \\
1 \\
0 \\
0 \\
1 \\
1 \\
0\end{array}$ & $\begin{array}{l}0 \\
\text { in } \\
1 \\
0 \\
0 \\
0 \\
+ \\
1 \\
1 \\
0\end{array}$ & $\begin{array}{l}0 \\
0 \\
0 \\
0 \\
0 \\
0 \\
\text { त̂ } \\
1 \\
0\end{array}$ & $\begin{array}{l}0 \\
\text { N } \\
0 \\
0 \\
0 \\
0 \\
0 \\
0 \\
0\end{array}$ & $\begin{array}{l}0 \\
+ \\
0 \\
0 \\
0 \\
0 \\
\text { i } \\
0\end{array}$ & $\begin{array}{l}0 \\
0 \\
0 \\
0 \\
0 \\
0 \\
5 \\
0\end{array}$ & $\begin{array}{l}0 \\
\infty \\
0 \\
0 \\
0 \\
0 \\
0 \\
0 \\
0\end{array}$ & $\begin{array}{l}8 \\
\Phi \\
5 \\
0 \\
5 \\
5 \\
0 \\
\infty\end{array}$ \\
\hline \multicolumn{12}{|l|}{ Центральный } \\
\hline 2019 г. & - & 1 & 9 & 6 & 1 & - & 1 & - & - & - & - \\
\hline 2020 г. & 5 & 9 & 2 & 1 & - & 1 & - & - & - & - & - \\
\hline \multicolumn{12}{|l|}{ Северо-Западный } \\
\hline 2019 г. & - & 1 & 1 & 4 & 3 & 1 & - & - & - & - & - \\
\hline 2020 г. & 1 & 2 & 3 & 2 & 2 & - & - & - & - & - & - \\
\hline \multicolumn{12}{|l|}{ Южный } \\
\hline 2019 г. & - & - & - & 3 & 2 & 2 & 1 & - & - & - & - \\
\hline 2020 г. & - & - & 3 & 1 & 3 & 1 & - & - & - & - & - \\
\hline \multicolumn{12}{|l|}{ Северо-Кавказский } \\
\hline 2019 г. & - & - & - & - & - & 1 & 2 & 1 & - & - & 3 \\
\hline 2020 г. & - & - & - & - & 1 & 1 & 1 & 1 & - & - & 3 \\
\hline \multicolumn{12}{|l|}{ Приволжский } \\
\hline 2019 г. & - & - & 1 & 6 & 5 & 2 & - & - & - & - & - \\
\hline 2020 г. & - & 6 & 3 & 4 & 1 & - & - & - & - & - & - \\
\hline \multicolumn{12}{|l|}{ Уральский } \\
\hline 2019 г. & - & - & 1 & - & 2 & - & - & - & 1 & - & - \\
\hline 2020 г. & - & 1 & 1 & 1 & - & - & - & 1 & - & - & - \\
\hline \multicolumn{12}{|l|}{ Сибирский } \\
\hline 2019 г. & - & - & - & 2 & 3 & 3 & - & 1 & - & - & 1 \\
\hline 2020 г. & - & - & 3 & 2 & 3 & - & - & 1 & - & - & 1 \\
\hline \multicolumn{12}{|l|}{ Дальневосточный } \\
\hline 2019 г. & - & - & - & - & 5 & 3 & 2 & - & 1 & - & - \\
\hline 2020 г. & - & - & 1 & 3 & 3 & 1 & 2 & - & 1 & - & - \\
\hline
\end{tabular}

ством РФ. С целью повышения государственной поддержки семей, имеющих детей, сохраняется предоставление материнский капитал при рождении первого ребенка в размере 483, 88 тыс. руб., а при появлении второго и третьего ребенка материнский капитал увеличивается на 155,55 тыс. руб. и до 639,43 тыс. руб. соответственно. С 1 января 2021 г. установлен максимальный размер пособия по уходу за первым, вторым и последующими детьми до 1,5 лет в размере 29,60 тыс. руб. при минимальном размере пособия 7082,85 тыс. руб.

Факторы успешности демографической политики РФ - это: поступательное социальноэкономическое развитие всех регионов, снижение уровня дифференциации жизни населения, повышение уровня социализации общества [7, c.110].

Демографические процессы всегда отражают ситуацию в сфере труда и занятости, уровня жизни населения, развития системы здравоохранения, осуществления мер социальной поддержки, поэтому без комплексного решения всех проблем улучшения демографической ситуации в стране не произойдет.

Продолжающееся старение населения в регионах страны приводит к дефициту рабочей силы, в связи с чем «происходит увеличение демографической нагрузки на трудоспособное население, обостряются проблемы с пенсионным обеспечением и выплатами социальных пособий» $[8$, с. 154]. 
Учитывая значительную дифференциацию регионов РФ по самым различным характеристикам, начиная от природно-климатических, культурных, национальных и заканчивая эко- номическими и экологическими, исследование естественной убыли населения следует проводить в разрезе отдельных регионов [9, с. 127].

\section{Библиографический список}

1. Указ Президента РФ от 09.10.2007 № 1351 (ред. от 01.07.2014) «Об утверждении Концепции демографической политики Российской Федерации на период до 2025 года» // Собрание законодательства РФ. 2007. № 42. Ст. 5009, 2014. № 27. Ст. 3754.

2. Томов, Н.Е. Анализ факторов, оказывающих влияние на уровень рождаемости населения / Н.Е.Томов, К. В.Бутусов, Т. В. Ямщикова // Modern Science. - 2021.- № 5-2.- С. 102-104.

3. Кожевникова. Н.И.Естественная убыли населения России / Н.И. Кожевникова, Л.Л. Рыбаковский, О.Л.Рыбаковский // II Всероссийский демографический форум с международным участием: материалы форума, Москва, 04-04 декабря 2020 года. - Москва: Объединенная редакция, 2020.- С. 181-184.

4. Бабич, С.Г. Анализ современной демографической ситуации в Российской Федерации / С. Г. Бабич, Э.А. Ярных // Экономические науки. - 2018. - № 166.-С. 141-150.

5. Указ Президента РФ от 07.05.2018 № 204 «О национальных целях и стратегических задачах развития Российской Федерации на период до 2024 года». Интернет-ресурс http://www.kremlin.ru/events/president/ news/57425 (дата обращения 02.06.2021).

6. Рыбаковский, Л.Л. Демографическое развитие России: динамики, компоненты и их результативность / Л.Л. Рыбаковский, Н.И. Кожевникова // Образование и еаука в России: состояние и потенциал развития.2020.- № 5. - C. 54-65.- DOI 10.19181/obrnaukru.2020.3.

7. Рыбаковский, О.Л. Демографическая политика: определение, структура, цели / О. Л.Рыбаковский, О. А. Таюнова // Наука. Культура. Общество. - 2019. - № 1.- С. 100-111.

8. Звягинцева, Ю.А. регулирование рынка труда в регионах с естественной убылью и миграционным оттоком населения / Ю.А. Звягинцева, Л.Л. Алехина, Е.В.Трошина // Вестник ОрелГИЭТ. - 2019. № 3(49).- С. 150-155.- DOI 10/36683/2076-5347-2019-3-40-150-155.

9. Бантикова О. И., Туктамышева Л. М. Оценка состояния естественного движения населения в регионах РФ // Вестник НГИЭИ. 2021. № 3 (118). С. 125-137. DOI: 10.24412/2227-9407-2021-3-125-137.

10. Федеральная служба государственной статистики/ Естественное движение населения в разрезе субъектов Российской Федерации. Интернет-ресурс https://rosstat.gov.ru/storage/mediabank/N8GgJ5B/edn04-2021. htm (дата обращения 20.05-05.06. 2021). 